\title{
5-hydroxymethylcytosine profiling as an indicator of cellular state
}

DNA methylation is widely studied in the context of cancer. However, the rediscovery of 5-hydroxymethylation of DNA adds a new layer of complexity to understanding the epigenetic basis of development and disease, including carcinogenesis. There have been significant advances in techniques for the detection of 5-hydroxymethylcytosine and, with this, greater insight into the distribution, regulation and function of this mark, which are reviewed here. Better understanding of the associated pathways involved in regulation of, and by, 5-hydroxymethylcytosine may give promise to new therapeutic targets. We discuss evidence to support the view of 5-hydroxymethylcytosine as a unique and dynamic mark of cellular state. These 5-hydroxymethylcytosine profiles may offer optimism for the development of diagnostic, prognostic and predictive biomarkers.

\section{KEYWORDS: cancer cellular state epigenetics hydroxymethylcytosine}

Epigenetic processes are associated with the regulation of gene expression through the chemical tagging of chromatin and DNA, which can alter their interaction with transcription factors [1]. Fundamentally, the field of epigenetics is concerned with inherited (but potentially reversible) changes in gene expression or cellular phenotype that do not rely on alterations to the underlying DNA sequence [1]. This definition has been broadened to include nonheritable histone modifications and transient changes associated with DNA repair or cell-cycle phases, such that modification of DNA, RNA and histones is broadly viewed as 'epigenetic' in character [2]. From this perspective, dynamic changes in DNA and histone modifications can be observed as embryogenesis proceeds in somatic, stem and primordial germ cells, which correlate with dynamic changes in gene expression [3-5]. These epigenetic signatures are characteristic of a particular cell type as they help define the associated transcriptome; this is most obvious in disease states such as cancer, which exhibit altered epigenetic and transcriptomic profiles [6-10].

DNA modifications are found to exist at cytosine bases in $\mathrm{CpG}$ dinucleotide sequences. Historically, the most widely studied modification of DNA is the incorporation of a methyl group onto the fifth carbon of a cytosine base to form 5-methylcytosine $(5 \mathrm{mC})$ [11]. This heritable epigenetic mark has been demonstrated to be present in all vertebrates and is proposed to be essential for normal development and cellular survival. The necessity of $5 \mathrm{mC}$ is highlighted with the dramatic global loss of $5 \mathrm{mC}$, altered gene expression patterns and embryonic lethality with targeted inactivation of the enzymes responsible for the initiation and maintenance of normal methylation patterns (the DNA methyltransferases [Dnmt1-3]) in mice [12-14]. Functionally, promoter $5 \mathrm{mC}$ contributes to the regulation of transcription at associated genes and has also been implicated in genomic imprinting, X-chromosome inactivation, tissuespecific gene regulation and retrotransposon silencing [15]. At the same time, potential roles for DNA methyltrasferase enzymes independent of their catalytic activity should not be ignored [16,17].

As originally proposed, DNA methylation was generally viewed as a stable epigenetic modification [18]. The preference of DNMT1 for hemimethylated substrates made it ideally suited to establish stable differentiated states in the absence of genetic mutation [19]. On the other hand, large-scale loss and reaccumulation of $5 \mathrm{mC}$ during murine embryogenesis and cellular differentiation indicated that DNA methylation profiles are 'reprogrammable' [4]. The identification of the molecular pathways underpinning DNA demethylation has a checkered history [20]. The recent identification of TET proteins as potential regulators of DNA methylation patterns through the oxidative conversion of $5 \mathrm{mC}$ to 5 -hydroxymethylcytosine $(5 \mathrm{hmC})$ has sparked intense activity in this research area [21]. There has been a growing body of inquiry into the function, dysregulation and potential significance of $5 \mathrm{hmC}$ in physiology

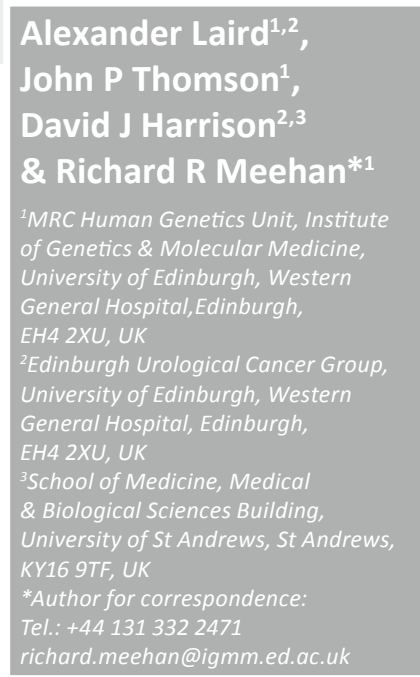

Future
Medicine $\mathrm{fS}$ art of 
and pathology $[22,23]$. This article will review the technologies for $5 \mathrm{hmC}$ detection and the insights this has given us into $5 \mathrm{hmC}$ function. This will provide the foundations to discuss tissue-specific profiles and disease-specific changes, which may imply that $5 \mathrm{hmC}$ is important in the pathogenesis of cancer or potentially useful as an indicator of disease state.

\section{Discovery \& technology}

$5 \mathrm{hmC}$ was described in 1952, having been identified in DNA from bacteriophages and viral DNA [24]. It took 20 years before the modification was first described in mammals, with the isolation of $5 \mathrm{hmC}$ carried out in rat, mouse and frog brains, as well as rat livers, at a yield of approximately 20 and $6 \%$ of cytosine, respectively [25]. However, these levels appeared too high and were not reproducible and, as such, were not widely accepted [26]. It was after the investigative discovery of $5 \mathrm{hmC}$ in murine neuronal cells in 2009 that the interest in this modified base was reignited [27]. While aiming to compare quantitative differences in $5 \mathrm{mC}$ between Purkinje and granule cell nuclei, Kriaucionis et al. discovered an unusual DNA nucleotide using thin layer chromatography [27]. They were then able to confirm this to be $5 \mathrm{hmC}$ with HPLC and mass spectrometry [27]. These techniques allowed accurate quantification of $5 \mathrm{hmC}$, but it was realized that standard techniques to assess $5 \mathrm{mC}$ could not differentiate the two [28-30].

Digestion of DNA before PCR with methylcytosine-sensitive HpaII and methyl-insensitive isoschizomer $\mathrm{MspI}$ is able to discriminate unmethylated cytosine and $5 \mathrm{mC}$. Differential quantification can also be achieved through PCR or sequencing after bisulfite conversion of cytosine to uracil through deamination, which is inhibited by methylation [31-33]. However, importantly, $5 \mathrm{hmC}$ as well as $5 \mathrm{mC}$ was shown to completely inhibit HpaII, as well as other methyl-sensitive restriction enzymes and $5 \mathrm{hmC}$ is also resistant to bisulfite deamination [29], thus preventing differentiation of $5 \mathrm{mC}$ from $5 \mathrm{hmC}$. During bisulfite conversion, $5 \mathrm{hmC}$ is converted to 5-methylenesulfonate, which was shown to be less efficiently amplified during PCR, thus raising the possibility of underestimation of these regions $[28,34]$. These findings highlighted the need for reassessment of previous methylation data to identify the contribution of $5 \mathrm{hmC}$ and the need for novel detection methods to allow accurate $5 \mathrm{hmC}$ localization, quantification and assessment of function, particularly as $5 \mathrm{mC}$ and $5 \mathrm{hmC}$ may occur in the same DNA fragments.
An overview of $5 \mathrm{hmC}$ detection methods is shown in Figure 1. $5 \mathrm{mC}$ enrichment through antibody immunoprecipitation has previously been established [35,36]. Initially, $5 \mathrm{hmC}$ polyclonal and monoclonal antibodies were used for semiquantitative purposes, as well as for immunoprecipitation and downstream analysis with PCR, array profiling or sequencing [37]. Bisulfite conversion of $5 \mathrm{hmC}$ to 5-methylenesulfonate and antibody immunoprecipitation of the converted base has also been demonstrated $[34,38]$. In addition to antibody-mediated methods of 5 hmC enrichment, several groups have since developed alternative enrichment strategies. Several of these are centered on the selective conversion of the modification into a glucosylated form following incubation with the T4 $\beta$-glucosyltransferase and modified dUTP. Following conversion of the $5 \mathrm{hmC}$ marks, these sugar-coated motifs can be purified by a variety of techniques such as selective biotinylation and streptavidin pull-down [34,39], or anaylzed further through selective methyl sensitive restriction enzyme digests [40,41]. Despite this, none of these methods allowed accurate localization of $5 \mathrm{hmC}$, which led to the development of single-base quantification with oxidative bisulfite sequencing (oxBS-seq) and TET-assisted bisulfite sequencing (TAB-seq).

oxBS-seq relies on the conversion of $5 \mathrm{hmC}$ to 5 -formylcytosine $(5 \mathrm{fC}$ ) with potassium perruthenate, which does not modify $5 \mathrm{mC}$ or cytosine. This $5 \mathrm{fC}$ is sensitive to bisulfite conversion to uracil. As such, standard bisulfite conversion can be performed on untreated DNA, which converts only cytosine to uracil, as well as the potassium perruthenate-treated DNA, which converts both cytosine and $5 \mathrm{fC}$. The two libraries can be subtracted for accurate localization and quantification of cytosine, $5 \mathrm{mC}$ and $5 \mathrm{hmC}$ [42]. TAB-seq is performed first by glucosylation of $5 \mathrm{hmC}$ to prevent oxidation. $5 \mathrm{mC}$ is subsequently oxidized with excess TET enzymes to 5-carboxylcytosine $(5 \mathrm{caC})$, without conversion of $5 \mathrm{hmC}$. The sample then undergoes standard bisulfite conversion, which converts the cytosine and $5 \mathrm{caC}$ (formerly $5 \mathrm{mC}$ ) to uracil with protection of the modified $5 \mathrm{hmC}$. The TAB-seq library is then compared with standard bisulfite sequence libraries for base-level localization and quantification [43]. However, despite these advances in single-base resolution profiling of $5 \mathrm{hmC}$, these techniques are largely still in development and have not been fully embraced by the epigenomic community. This is likely due to a number of factors: the development 
of reliable commercial kits for oxBS-seq and TAB-seq is still ongoing, particularly as TABseq requires highly active TET enzymes; second, many interested groups are still limited by the cost of sequencing; oxBS-seq may also be limited by the damage and degradation of genomic DNA by chemical oxidation conditions and repeated bisulfite treatments required for deamination. Nonetheless, these technological advances underpin our greater awareness of $5 \mathrm{hmC}$ distribution and fuel intellectual curiosity regarding its potential function and interpretation.

\section{Function \& distribution}

In 2009 Tahiliani and colleagues identified the TET enzymes and their role in the methylation cycle as potential demethylases, based on their similarity between mammalian $5 \mathrm{mC}$ and base $\mathrm{J}$ in kinetoplasids (a group of unicellular protozoa), which is involved in gene silencing [21]. They used a bioinformatics approach to identify mammalian homologs of the proteins involved in these conversions (JBP1 and JBP2: 2-oxoglutarate [2OG]- and $\mathrm{Fe}[\mathrm{II}]$-dependent oxygenases), hypothesizing that if present, these would be involved in $5 \mathrm{mC}$ modification [44]. This led to the discovery of the paralogous human proteins TET1, TET2 and TET3 [21], which were also demonstrated to be 2OG-and $\mathrm{Fe}(\mathrm{II})$-dependent enzymes. Overexpression of TET enzymes in human and mouse cells resulted in increased $5 \mathrm{hmC}$ and decreased $5 \mathrm{mC}$ detection, with a depletion of TET enzymes associated with a reduction of $5 \mathrm{hmC}[21,45,46]$. These findings suggested that the TET enzymes may cause oxidation of $5 \mathrm{mC}$ to $5 \mathrm{hmC}$ and led to studies investigating the function of $5 \mathrm{hmC}$. A number of groups hypothesized that $5 \mathrm{hmC}$ was an intermediate in a DNA demethylation pathway $[47,48]$.

The mechanisms of $5 \mathrm{hmC}$ involvement in demethylation were proposed to be both active and passive. In the passive model, the usual mechanism for maintenance of $5 \mathrm{mC}$ is disrupted. During cell division, DMNT1 is able to recognize hemimethylated DNA in concert with recruitment by UHRF1 [49-51]. This results in subsequent methylation of the daughter strand based on the pattern of the parent strand, thus maintaining a symmetrical pattern through cell division. However, DMNT1 has reduced binding to $5 \mathrm{hmC}$ compared with $5 \mathrm{mC}$ $[52,53]$. Therefore, the conversion of $5 \mathrm{mC}$ to $5 \mathrm{hmC}$ prevents DMNT1 binding to the parent strand with resulting loss of methylation on the

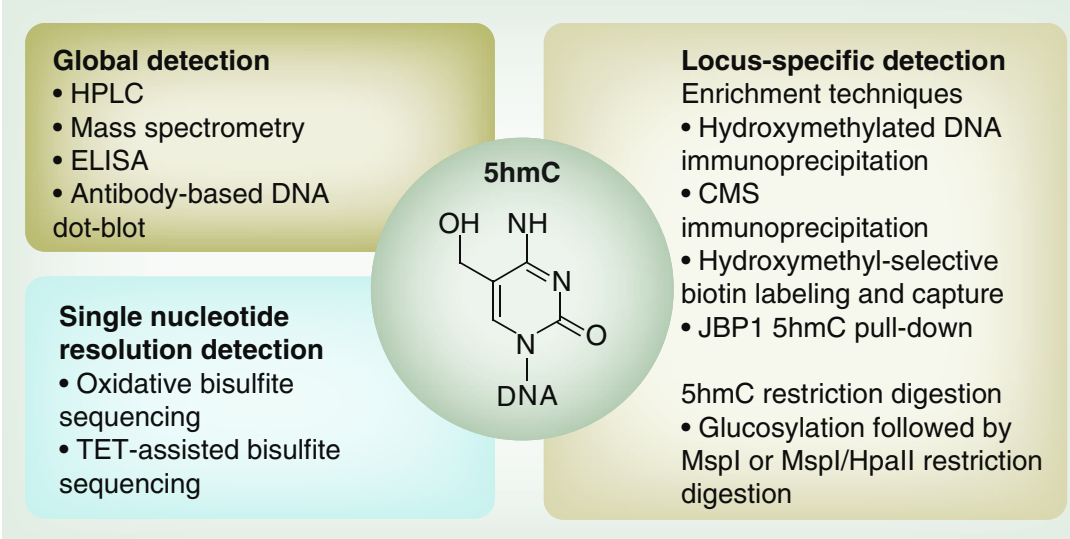

Figure 1. Global, locus-specific and single nucleotide resolution of 5-hydroxymethylation detection methods. HPLC, mass spectrometry , ELISA and DNA dot-blot techniques provide global assessment of $5 \mathrm{hmC}$ levels. Locusspecific assessment of $5 \mathrm{hmC}$ can be achieved through antibody immunoprecipitation of $5 \mathrm{hmC}$ directly or CMS following bisulphite conversion of $5 \mathrm{hmC}$ to CMS. Other locus-specific detection methods rely on the glucosylation of $5 \mathrm{hmC}$ with subsequent pull-down techniques, selective labeling with biotin and chemical capture or selective methyl-sensitive restriction enzyme digestion approaches. Single nucleotide resolution profiling of $5 \mathrm{hmC}$ can be achieved through two methods, either oxidative bisulfite sequencing or TET-assisted bisulfite sequencing. oxBS-seq relies on the oxidative conversion of $5 \mathrm{hmC}$ to 5 -formylcytosine by potassium perruthenate, which is susceptible to bisulfite conversion such as unmodified cytosine. While during TAB-seq, $5 \mathrm{hmC}$ is protected from bisulfite conversion and $5 \mathrm{mC}$ is made sensitive through glucosylation and oxidation to $5 \mathrm{hmC}$ and 5-carboxylcytosine, respectively. These unique oxBS-seq and TAB-seq libraries can be subtracted from standard bisulfite-sequence libraries to give profiling of relative $5 \mathrm{hmC}$ and $5 \mathrm{mC}$.

5hmC: 5-hydroxymethylation; CMS: 5-methylenesulfonate.

daughter strand. This has been supported by an in vivo study revealing passive $5 \mathrm{hmC}$ loss in the paternal mouse zygote during preimplantation [54]. Nonetheless, although the model of passive demethylation is supported by a number of groups, it has not been directly shown that the presence of $5 \mathrm{hmC}$ in early zygotes equates to a loss of $5 \mathrm{mC}$. The exact mechanism is not as clear, as the UHRF1 cofactor has been shown to bind with equal efficiency to $5 \mathrm{mC}$ and $5 \mathrm{hmC}$, therefore raising questions over the DMNT1 maintenance mechanism and the role of $5 \mathrm{hmC}$ in preventing such a mechanism from working [55]. Furthermore, a recent study confirmed that while exogenous UHRF1 in embryonic stem (ES) cells improves localization of DMNT1, it does not affect methylation dynamics [56]. There have also been a number of potential active pathways proposed for the DNA demethylation process (Figure 2).

It has been shown that the TET enzymes facilitate the progressive oxidation of $5 \mathrm{mC}$ to $5 \mathrm{hmC}$, and subsequently to the recently identified $5 \mathrm{fC}$ and $5 \mathrm{caC}$ derivatives [57-59]. The decarboxylation of $5 \mathrm{caC}$ has been proposed as a candidate route of demethylation, akin to the process of demethylation of thymine to uracil 


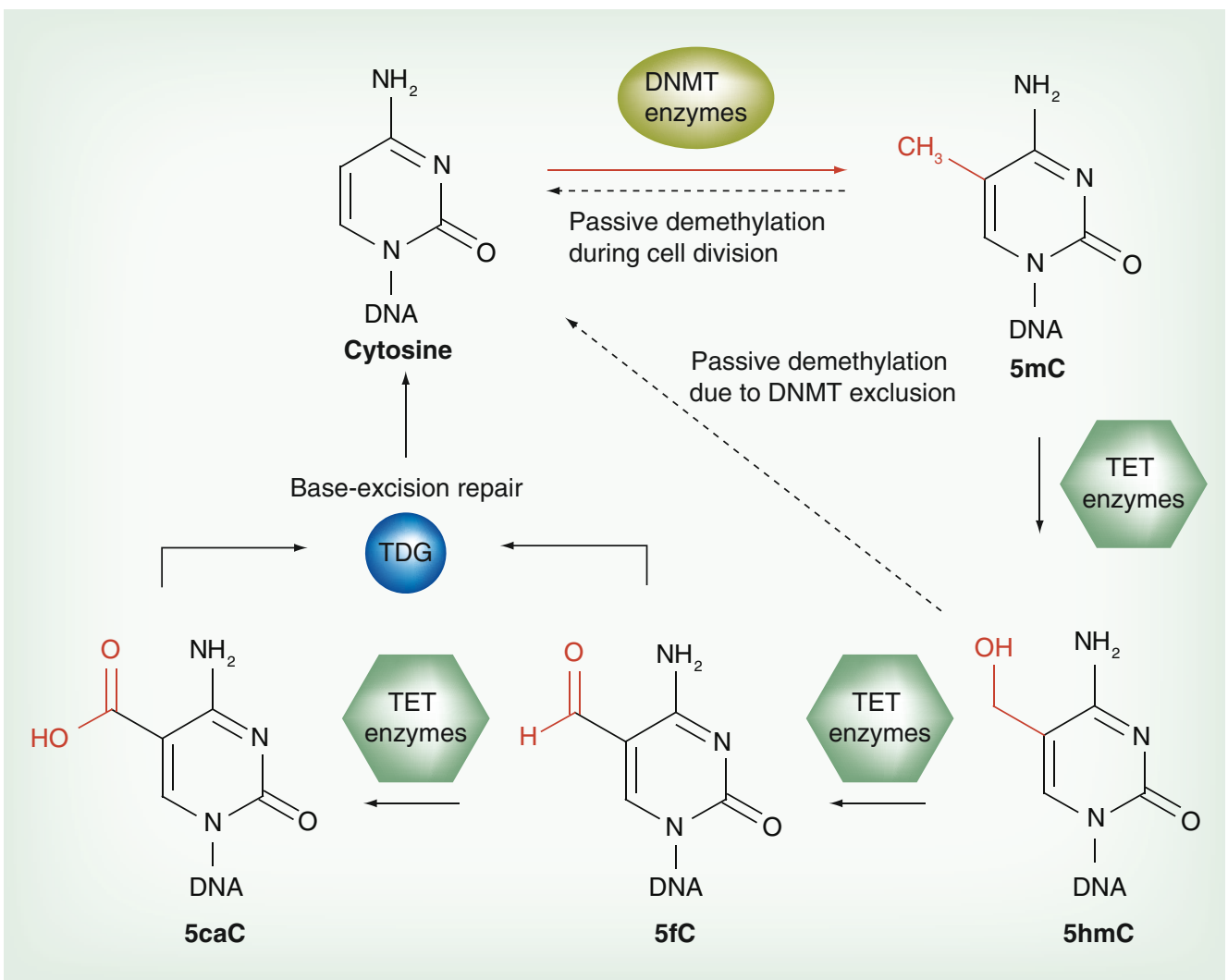

Figure 2. Proposed models of TET-mediated DNA demethylation pathways. Unmodified cytosine bases in a CpG dinucleotides can be directly methylated through the actions of the DNA methyltransferase enzymes. Demethylation is thought to be both passive (during cell division; dashed arrow) as well as active (through a series of enzymatic reactions). TET proteins can oxidize $5 \mathrm{mC}-$ modified bases into $5 \mathrm{hmC}$ and then onto $5 \mathrm{fC}$ and $5 \mathrm{caC}$ derivatives. The oxidized $5 \mathrm{fC}$ and $5 \mathrm{caC}$ bases are thought to provide suitable substrates for rapid demethylation to nonmodified cytosine via TDG-coupled base-excision repair. In contrast with these rapidly turned-over intermediates, 5hmC appears to remain stable in certain parts of the genome.

Black arrows: active methylation; dashed arrows: passive demethylation; red arrow: methylation. 5caC: 5-carboxylcytosine; 5fC: 5-formylcytosine; 5hmC: 5-hydroxymethylcytosine;

5mC: 5-methylcytosine.

in yeast [60], but no such carboxylase has yet been identified in mammals. Alternatively, it has been suggested that demethylation occurs through deamination of $5 \mathrm{hmC}$ to 5 -hydroxymethyluracil with subsequent base-excision repair, resulting in a nonmodified $\mathrm{CpG}$ dinucleotide [61-63]. Once more, the evidence supporting such a pathway has also been called into question. Despite the finding that the AID and APOBEC enzymes can deaminate $5 \mathrm{mC}$ in vitro, and that they are significantly expressed in murine tissue and primordial germ cells in which demethylation occurs $[64,65]$, they were found to have greater affinity for cytosine binding than for $5 \mathrm{mC}$ or $5 \mathrm{hmC}$. Additionally, overexpression of AID/APOBEC did not result in increased detection of deamination products or reduction in $5 \mathrm{fC}$ or $5 \mathrm{caC}$ [66]. Instead, the most likely mode of active demethylation appears to be regulated by TDG-mediated base-excision repair [57,67-71]. In two recent papers, both $5 \mathrm{caC}$ and $5 \mathrm{fC}$ were mapped across the genome of mouse ES cells for the first time, with extremely low levels of enrichment observed [70,71]. This is likely due to the fact that these modifications are not stable, but are instead rapidly turned over transient marks of active DNA demethylation. However, upon the reduction of the TDG enzyme by both shRNAi, as well as in a knockout model, ectopic regions of $5 \mathrm{fC}$ and $5 \mathrm{caC}$ become apparent and were seen over genic and promoter-proximal regions, with a particular enrichment over poised (H3K4mel but not H3K27ac-marked) enhancer elements. Taken together with the finding that depletion of the TDG enzyme in mouse ES cells leads to accumulation of $5 \mathrm{caC}$ to detectable levels, this suggests that this is a likely mechanism for active demethylation events [57]. Nevertheless, it is of note that the detection of $5 \mathrm{fC}$ and $5 \mathrm{caC}$ in the 
paternal pronucleus during mouse preimplantation and the dilution of these factors through replication, similar to that described for $5 \mathrm{hmC}$, may also suggest that these factors could be involved in a passive demethylation process [54,72]. While the involvement of $5 \mathrm{hmC}$ in the demethylation process appears highly plausible, the molecular mechanisms through which this occurs have yet to be unequivocally identified. It is clear that $5 \mathrm{hmC}$ is not solely an intermediate in this process (unlike the transient marks of $5 \mathrm{fC}$ and $5 \mathrm{caC}$ ) and is likely to have additional unique biological functions.

One such biological role may be associated with marking gene transcription. The conversion of $5 \mathrm{mC}$ to $5 \mathrm{hmC}$ affects the binding affinity of a number of proteins to DNA. There have been reports of reduced affinity of MBD1, MBD2, MBD4 and MeCP2 to 5hmC [73,74]. These are contrasted with reports of significant affinity by $\mathrm{MBD} 3$ and $\mathrm{MeCP} 2$ to $5 \mathrm{hmC}$ containing substrates $[75,76] .5 \mathrm{hmC}$ binding by $\mathrm{MeCP} 2$ has been reported in extracts derived from ES cells, but not in neuronal tissue, while $\mathrm{MeCP} 2$ was found to be a $5 \mathrm{mC}$ reader in mouse ES cells, neuronal progenitor cells and adult mouse brain tissue [77]. In this analysis, the protein-DNA interactions were dynamic with, for example, neuronal progenitor cell-specific binding of Uhrf2 to $5 \mathrm{hmC}$. Wdr76 preferentially binds to $5 \mathrm{hmC}$ and interacts with HELLS, a DNA helicase that has been previously implicated in regulating DNA methylation levels in cells $[78,79]$. While the exact consequences of altered protein binding have not been elucidated, it may suggest that $5 \mathrm{hmC}$ is an important contributor to the control of gene transcription through its ability to differentially interact with nuclear factors, in addition to DNA methylation reprogramming.

$5 \mathrm{hmC}$ occurs in $\mathrm{CpG}$ dinucleotides with an asymmetrical strand bias, with a G-rich preference in human ES cells [43]. In human somatic neural tissue, $5 \mathrm{hmC}$ is enriched in promoters and intragenic regions, but is largely absent from intergenic regions [80]. Moreover, $5 \mathrm{hmC}$ within gene bodies appears to be preferentially located at exons $[34,37,81]$ and is positively correlated with gene-expression levels [80], which mirrors findings from work on murine neuronal tissue [39]. In addition, further work on both human and mouse ES cells has shown genic $5 \mathrm{hmC}$ distribution to be related to gene expression with high $5 \mathrm{hmC}$ levels in the gene bodies of high- and intermediate-expressed genes compared with low-expressed genes [39,82]. This may suggest that there is a mechanism that allows TET enzymes to target genes [41], presumably for gene activation, although the causative effect on gene regulation is yet to be shown. TET1, 2 and 3 have now been identified as interaction partners for OGT. Chromatin immunoprecipitation-sequencing experiments demonstrate that OGT binding sites on chromatin are cooccupied by TET enzymes in mouse ES and somatic cells [83-86]. In addition, TET proteins and OGT activity can promote binding of the SET1/COMPASS H3K4 methyltransferase, SETD1A, to chromatin [84]. TET2 knockout in mouse bone marrow leads to decreases in global $N$-acetyl glycosylation and $\mathrm{H} 3 \mathrm{~K} 4 \mathrm{me} 3$, notably at several key regulators of hematopoiesis. Together, these results suggest a novel pathway by which the TET enzymes themselves may be required for transcriptional activation in the absence of their catalytic function. Figure 3 illustrates the proposed TET, OGT and SET1 interactions for gene transcription, with typical $5 \mathrm{mC}$ and $5 \mathrm{hmC}$ profiles associated with the active gene.

Interestingly, in human ES cells, $5 \mathrm{hmC}$ has been found to be most abundant at regions of low CpG density, and promoters with high CpG content (e.g., CpG islands) have almost complete absence of $5 \mathrm{hmC}[43,82]$. Study of human ES cells also revealed that $5 \mathrm{hmC}$ is located at regions with a GC skew, in which Gs are enriched over Cs in the $5^{\prime}$ end of the region with the converse in the $3^{\prime}$ end [87]. It has previously been proposed that GC skew may occur at sites of replication termination and recombination hotspots [88-90] and, as such, $5 \mathrm{hmC}$ may also mark these sites [87].

A major modifier of both global and locusspecific $5 \mathrm{hmC}$ profile is tissue type [41]. Interestingly, in both mouse and human tissues, the brain, which has a low proliferative rate, had the highest level of $5 \mathrm{hmC}$, while blood, which undergoes significant proliferation during hematopoiesis, had the lowest [41]. This same study also confirmed loss of $5 \mathrm{hmC}$ from cells that have adapted to culture. Together, these findings may reinforce the role of $5 \mathrm{hmC}$ in the passive demethylation process, in which the proliferative rate of tissue and cells affects $5 \mathrm{hmC}$ levels. This hypothesis is strengthened by the findings of Jin et al. who demonstrated with immunohistochemistry the mutual exclusivity of Ki67, a marker of proliferation and $5 \mathrm{hmC}$ in tissue [91]. However, the finding of reduced TET expression upon cell culture may suggest that this is not solely related to proliferation [41]. 


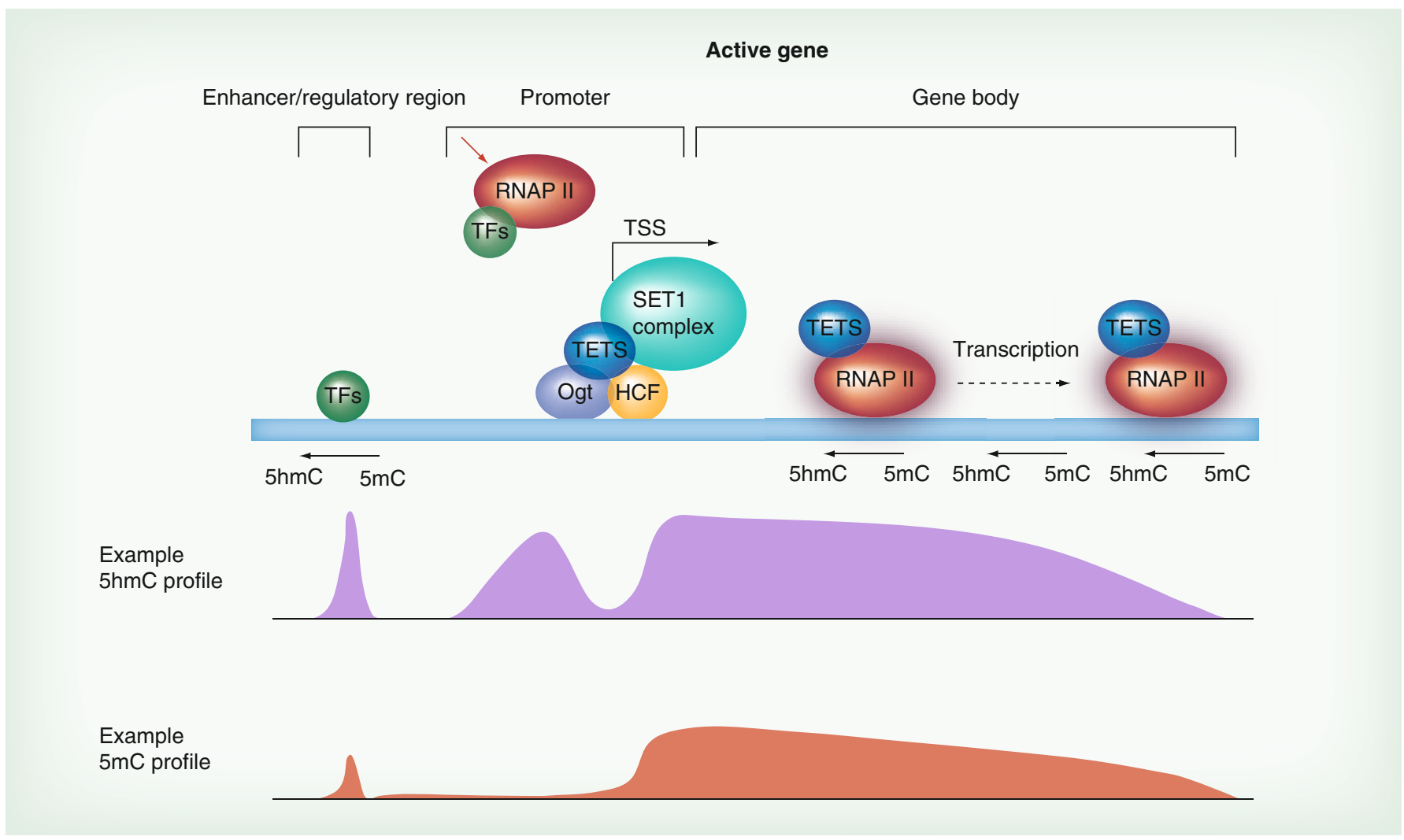

Figure 3. Proposed model of 5-methylcytosine, 5-hydroxymethylcytosine and TET distribution associated with gene transcription. Activation of gene expression can occur through the active demethylation of regions around the TSS (loss of $5 \mathrm{mC}$ through a 5hmC intermediate) with elevated promoter and gene body $5 \mathrm{hmC}$ levels allowing the binding and elongation of the RNAP-II complex, probably in concert with histone modification changes (not shown). Conversion of $5 \mathrm{mC}$ into $5 \mathrm{hmC}$ (and further derivatives) is mediated by the TET proteins (blue). TET proteins have been show to interact with OGT, as well as the HCF1, component of the H3K4 methyltransferase SET1/COMPASS complex, resulting in altered chromatin environments (OGT, HCF1 and SET1 complex: yellow). TDG (not shown) is proposed to complete this promoter-specific demethylation through base-excision repair, while regions lacking TDG lead to the accumulation of $5 \mathrm{hmC}$ (e.g., gene bodies and enhancers), perhaps by tracking the RNAP II complex in the case of gene bodies. Typical $5 \mathrm{hmC}$ (purple) and $5 \mathrm{mC}$ (red) profiles at an actively transcribing gene are shown above.

5hmC: 5-hydroxymethylcytosine; 5mC: 5-methylcytosine; TF: Transcription factor; TSS: Transcription start site.

\section{$5 \mathrm{hmC}$ profiling defines cellular state}

Recently, accumulation of $5 \mathrm{hmC}$ in the developing mammalian brain has been shown to occur in a partly independent process from methylation at CpGs [92]. The development of adult $5 \mathrm{hmC}$ patterns in the brain have also been shown to develop in utero, although the $5 \mathrm{hmC}$ pattern in the fetal frontal cortex is unique to the stage of fetal development [92]. Furthermore, developmentally downregulated genes show enrichment of $5 \mathrm{hmC}$ in the fetal frontal cortex, but not in adults, supporting the correlation of reduced transcription with loss of $5 \mathrm{hmC}[76,92]$. These findings support the role of $5 \mathrm{hmC}$ as a marker of cellular state, which has been demonstrated systematically using a nongenotoxic carcinogen (NGC) liver tumor mouse model [93,94].

It is known that the epigenome can be perturbed in response to a group of chemicals called NGCs. Exposure to the NGC phenobarbital (PB) can lead to an increase in the incidence of spontaneously and chemically induced liver tumors in rodents and significantly promotes hepatic tumor incidence in $\mathrm{B} 6 \mathrm{C} 3 \mathrm{~F} 1$ mice, as well as increasing the size of the tumors themselves [95-99].

PB exposure leads to the expression of genes that depend on activation of the constitutive active androstane receptor. It was recently suggested that $\mathrm{PB}$ activates the constitutive active androstane receptor by inhibiting EGF receptor signaling [100]. Recent work in our laboratory shows that the distribution of $5 \mathrm{mC} / 5 \mathrm{hmC}$ is highly consistent between untreated individual mice of a similar age; yet subtle changes during liver maturation in a transcriptionally dependent manner occur [93]. Following exposure to $\mathrm{PB}$, there are staged transcriptional responses corresponding to dose exposure that strongly correlate with promoter-proximal region $5 \mathrm{hmC}$ levels, suggesting that $5 \mathrm{hmC}$ may be 
the mechanism that facilitates transcriptional changes $[93,94]$. Furthermore, reciprocal changes for both $5 \mathrm{mC}$ and $5 \mathrm{hmC}$ in response to $\mathrm{PB}$ suggest that active demethylation may be taking place at each set of these loci, via a $5 \mathrm{hmC}$ intermediate. It is possible that these changes in $5 \mathrm{mC}$ and $5 \mathrm{hmC}$ result from variation in cell populations and cellular heterogeneity in response to stimuli. However, the dynamics of $5 \mathrm{hmC}$ turnover appear to be very rapid, implying that these reflect true cell autonomous changes in the epigenome. As such, this work suggests $5 \mathrm{hmC}$ profiling can be used as an indicator of cell states during organ maturation and drug-induced responses, and provides novel epigenetic signatures for NGC exposure. Many regions were seen to change dramatically in their $5 \mathrm{hmC}$ levels following drug exposure. By focusing on the promoter regions of strongly induced genes, it was observed that these contained elevated levels of 5hmC-marked DNA, as well as increased levels of $\mathrm{H} 3 \mathrm{~K} 4 \mathrm{me} 2$, a histone modification associated with gene activation [94]. Conversely, these same promoter regions were found to lose $5 \mathrm{mC}$. $\mathrm{PB}$-induced genes gained $\mathrm{H} 3 \mathrm{~K} 36 \mathrm{me} 3$ in the body of the gene, while losing the repressive histone mark, H3K27me3.

Importantly, this work revealed that reproducible interindividual epigenetic perturbations, namely changes to the hydroxymethylome, can be observed following $24 \mathrm{~h}$ of drug dosing and that these changes persist or expand over several months as the length of exposure continues [93]. This raises the exciting possibility that $5 \mathrm{hmC}$ is a potential biomarker of exposure to particular environmental stimuli or risk factors in disease development. While $5 \mathrm{mC}$ patterns have been demonstrated to be changed in response to environmental stimuli such as smoking [101], $5 \mathrm{hmC}$ may offer additional benefit as a marker of specific exposure. This was demonstrated with the PB NGC model, as global $5 \mathrm{hmC}$ perturbations alone were sufficient to stratify drugexposed individuals from the control set, while $5 \mathrm{mC}$ and selective histone modifications alone did not always reliably report exposure [93,94]. It would be important to confirm whether these changes remain present and identifiable long after exposure in this model, and whether these observations in a mouse model system are transferable to human disease.

The measurable and reproducible changes in $5 \mathrm{hmC}$ in response to a drug could conceivably be used to monitor epigenetic changes in the tissue as an indication of a real-time response. Furthermore, the alterations observed in response to a previously considered 'nonepigenetic modulator' such as $\mathrm{PB}$, could suggest that these profiles may be used to monitor traditional therapies, as well as newer treatments targeted at epigenetic components. One might expect a reversal of the 'cancer signature' to that of the 'normal tissue signature' on successful treatment of a disease in a tissue-specific manner. This would be particularly important in oncological management, where there is a void of sensitive and specific markers of disease response, and patients often undergo repeated ionizing imaging to assess disease burden.

\section{$5 \mathrm{hmC}$ patterns in cancer}

Cancer-related $5 \mathrm{hmC}$ pattern changes and possible underlying mechanisms are summarized in Box 1. Reduction in $5 \mathrm{hmC}$ is well reported in a number of cancers and cell lines corresponding to prostate, breast, colon, lung, brain, liver, kidney and melanoma, compared with the associated normal tissue $[41,91,102]$. This hypohydroxymethylation may be due to the cellular replication-related loss of $5 \mathrm{hmC}$ described above, reflecting the increased proliferative

\footnotetext{
Box 1. Summary of changes in 5-hydoxymethylcytosine patterns and possible underlying mechanisms seen in cancer.

- Cancer-associated hydroxymethylcytosine patterns

- General loss of 5hmC

- Cancer-specific redistribution with enrichment, particularly at oncogenic gene activators

- Possible mechanisms for 5hmC changes in cancer

Replication-related passive demethylation and loss of hydroxymethylcytosine

Misexpression or mutation of TET enzymes, which are responsible for the oxidative conversion of $5 \mathrm{mC}$ to $5 \mathrm{hmC}$

- Inhibition of the essential TET cofactor, $\alpha$-ketoglutarate, through mutation of isocitrate dehydrogenase or other Krebs cycle enzymes, such as fumerate hydratase or succinate dehydrogenase

5mC: 5-methylcytosine; 5hmC: 5-hydroxymethylcytosine.
} 
rate of the cancer compared with normal tissue. However, there was no correlation between levels of $5 \mathrm{hmC}$ and $5 \mathrm{mC}$ staining in colorectal or prostate tumors [102], suggesting the presence of alternative mechanisms to the general global hypomethylation reported in cancer [103].

Another possible explanation for altered $5 \mathrm{hmC}$ patterns in cancer is the misexpression of TET enzymes, which are responsible for $5 \mathrm{hmC}$ production. While TET3 has been implicated in the $5 \mathrm{mC}$ decrease, and simultaneous $5 \mathrm{hmC}$ increase in the male pronucleus upon zygote formation prior to cell division [104-106], there has been no association between TET3 expression and cancer reported so far.

Prior to the rediscovery of $5 \mathrm{hmC}$ with the subsequent appreciation of TET involvement in the methylation cycle, TET1 was identified as a fusion partner of the mixed-lineage leukemia in the ten-eleven chromosomal translocation $\mathrm{t}(10 ; 11)(\mathrm{p} 12 ; \mathrm{q} 23)$ in rare cases of acute myeloid leukemia (AML) $[107,108]$. Whereas the role of TET1 in these AML cases is independent of its regulation of $5 \mathrm{hmC}$, subsequent loss of TET1 and changes in $5 \mathrm{hmC}$ have been shown in a number of solid tumors. In prostate and breast cancer, TET1 has been shown to inhibit cancer growth and metastases through tissue inhibitors of metalloproteases (TIMPs). Conversely, loss of TET1 is associated with the de novo methylation of TIMP2 and TIMP3 and associated gene repression, and correlates with poor survival rates in breast cancer patients [109]. The HMGA2-TET1-HOXA9 pathway is coordinately regulated in breast cancer and has been reported to encompass a prognostic signature for patient survival [110]. Expression of TET1 and HOXA9 suppresses breast tumor growth and metastasis in mouse xenografts. Others have demonstrated that loss of $5 \mathrm{hmC}$ was associated with downregulation of TET1 in hepatocellular carcinoma and this was associated with poorer overall survival [111]. Clearly, these studies suggest that the loss of TET1 may have an important role in the development of an aggressive phenotype in cancer.

As well as the alterations of TET1 in cancers, TET2 has been implicated in melanoma progression. Global loss of $5 \mathrm{hmC}$ was demonstrated in malignant melanoma and this correlated with loss of TET expression, particularly TET2 [112]. Furthermore, these global changes in $5 \mathrm{hmC}$ were associated with Breslow score, mitotic rate, pathological tumor stage and tumor ulceration, all currently used prognostic indicators in malignant melanoma. Loss of $5 \mathrm{hmC}$ in melanoma patients was also correlated with poorer survival on Kaplan-Meier survival analysis [112].

A study in pancreatic cancer has shown that there is also a cancer-specific redistribution of $5 \mathrm{hmC}$, with enrichment in particular oncogenic gene activators [113]. The highly tissue-specific and dynamic patterns observed for $5 \mathrm{hmC}$ distribution could be vital in defining the tissue of origin of a metastatic cancer, which in turn may aid the overall diagnosis and subsequent treatment regime [8]. These findings, combined with the cell- and tissue-specific distribution of $5 \mathrm{hmC}$, suggest a possible prognostic role for $5 \mathrm{hmC}$ in cancer, although multivariate analysis has not been performed to confirm whether $5 \mathrm{hmC}$ could be independently significant. Furthermore, overexpression of TET 2 in melanoma cells resulted in subsequent partial re-establishment of $5 \mathrm{hmC}$ profiles with inhibition of invasion on cell culture-based invasion assays and tumor growth in vitro using xenograft models [112]. This suggests possible success with therapeutic manipulation of TET2, but also provides support for $5 \mathrm{hmC}$ as a marker of response to treatment.

Despite these changes in TET expression in cancer, TET has not been seen to be frequently mutated in the large-scale sequencing studies of solid malignancies [114-117]. This would suggest that there are mechanisms, other than mutations of the TET genes, which cause these changes. Therefore, further work is required to understand the mechanisms underpinning TET-related $5 \mathrm{hmC}$ changes in cancer.

Nonetheless, mutations in TET2 have been demonstrated in all subtypes of myeloid malignancies, and TET2 is the most commonly mutated gene in myelodysplastic syndrome (MDS) [118-123]. These mutations are associated with transformation of MDS to AML, as well as poorer survival in AML patients [118]. Lossof-function mutations in TET2 have also been demonstrated as a recurrent event in human lymphomas [124]. The breadth of hematological malignancy with TET2 mutations may support this as an early event in disease development. Moreover, unlike the regulatory control of TET enzymes on $5 \mathrm{hmC}$ in murine ES cells to maintain pluripotency [125], it has been shown that this mechanism has the reverse function for control of hematopoietic stem and progenitor cell homeostasis. A number of studies using TET2 mouse models have shown that TET2-null mice have increased hematopoietic stem cell numbers and that these cells are able to self-renew in culture. Furthermore, although these knockout mice are viable, they die early as a result 
of hematological malignancy [124,126-128]. These findings, supported by the higher TET 2 expression in differentiated blood cells compared with progenitor cells [128], strengthens the argument that the correlation of reduced $5 \mathrm{hmC}$ and TET2 mutation in MDS, and other hematological malignancies, is due to an early event in hematopoiesis, likely to be affecting hematopoietic stem and progenitor cells [124]. Importantly, if these findings are confirmed then it would indicate that disease treatments would need to focus on these hematopoietic stem cells.

The third possible contributing mechanism for the general loss of $5 \mathrm{hmC}$ in cancer is through inhibition of TET cofactors. As previously described, TET enzymes are 2OG-dependant, which is produced through catalytic oxidative carboxylation of isocitrate by isocitrate dehydrogenases (IDHs) in the Krebs cycle [129,130]. There are two homologs of this enzyme, IDH1 and IDH2, which catalyze the same reaction. Gain-of-function mutations of both IDH1 and IDH2 have been identified in cancer cells. These mutations produce the R-enantiomer of the oncometabolite 2-hydroxyglutarate (2-HG) $[131,132]$. Both the R-and S-enantiomers of 2-HG are structurally similar to $2 \mathrm{OG}$ and can antagonize the 2OG-dependant reaction [130,133,134], thus inhibiting TET-mediated $5 \mathrm{mC}$ to $5 \mathrm{hmC}$ conversion. Significant downregulation of IDH2 in melanomas compared with benign nevi has been shown [112]. Furthermore, overexpression of IDH2 in the $B R A F^{\mathrm{V} 600 \mathrm{E}}$ zebrafish melanoma models significantly increased $5 \mathrm{hmC}$ levels, with improved progression-free survival [112], highlights the possible therapeutic benefit of targeting this pathway when mutated.

Recently, through transfection of mutant IDH1 in a leukemia cell line (TF1), IDH has been shown to be oncogenic through the development of growth factor independence and impaired differentiation [135]. Interestingly, knockdown of TET2 recapitulated these findings, suggesting that IDH inhibition of TET may be the mechanism of action. However, paradoxically, while the $I D H 1$ mutant R-enantiomers, but not the $S$-enantiomers, resulted in the hallmark leukemic transformations, the $S$-enantiomers are the greater inhibitor of TET2 [135]. This raises the possibility that other 2OG-dependant pathways, other than inhibition of TETs may be involved. Nonetheless, the changes in growth factor dependence and impaired differentiation induced by IDH1 mutation were demonstrated to be reversible through pharmacological blockade of 2-HG. While we have indicated that there are potential problems of studying TET and $5 \mathrm{hmC}$ in cell culture, and clearly further work is required to understand the subsequent mechanism of tumorigenesis following $I D H$ mutation, this does raise the possibility of success for 2-HG-blocking compounds as therapeutic agents.

As well as the association of IDH dysregulation in melanoma, mutations in IDH1 and IDH2 have been seen in hematological, brain, colonic, prostate and thyroid tumors [115,132,136-140]. Interestingly, mutations in IDH1 have been identified in up to $70 \%$ of grade 2 and 3 gliomas and secondary glioblastomas, with most of the remainder harboring mutations in IDH2 [138]. These mutations appeared early in tumor development and their presence in both astrocytoma and oligodendroglioma subtypes suggests that these may be early mutations in the neural stem cells, a common theme in these $5 \mathrm{hmC/TET/IDH} \mathrm{abnormalities.} \mathrm{However,}$ while IDH mutations in melanoma and cholangiocarcinoma studies have correlated with loss of $5 \mathrm{hmC}[112,141]$, this has not been universally demonstrated in brain tumors. IDH1 mutation has, however, been linked with a distinct pattern of CpG promoter hypermethylation [142], which could be interpreted as being a result of a failure in the conversion of $5 \mathrm{mC}$ to $5 \mathrm{hmC}$ through TET inhibition. In addition, some brain tumors have been shown to have prognostically lower $5 \mathrm{hmC}$ levels than normal brain tissue. Despite this, there has been no correlation with IDH mutations and $5 \mathrm{hmC}$ levels in these cancers to date [91,143-145]. It therefore raises the possibility that IDH mutations may drive oncogenesis through alternative pathways to $5 \mathrm{hmC}$. There are a number of other 2OG-dependant pathways, including the hypoxia-inducible factor propylhydroxylase [146] and JMJC domain-containing histone demethylases [147], which could be targeted to promote oncogenesis. Furthermore, mutations in succinate dehydrogenase and fumarate hydratase identified in a number of human cancers including pheochromocytoma, paraganglioma and papillary renal cell carcinoma, result in the accumulation of succinate and fumerate, respectively [148-151]. These also inhibit 2OG-dependant deoxygenases, and it is only recently that the potential impact on TET activity has been appreciated with alterations of genome-wide DNA methylation being identified $[152,153]$. The complete extent of these changes has not been investigated, neither has the role of $5 \mathrm{hmC}$. These findings emphasize the likely importance of interactions between the Krebs cycle, epigenomic regulation and cancer. 


\section{Future perspective \& clinical applicability}

Four years following the rediscovery of $5 \mathrm{hmC}$, there has been significant reassessment and progress in our knowledge of methylation, hydroxymethylation and associated changes in disease states such as cancer. While the interactions of these are complex, and likely tissue-specific, there is clear potential for clinical translation of some of these findings following more in-depth study. These proposed potential strategies for the use of $5 \mathrm{hmC}$ as a biomarker could help us to achieve personalized medicine in which we can stratify high-risk patients, prognosticate risk of recurrence, predict sensitivity to treatment and monitor therapeutic response (Figure 4). These possible applications will only be realized if there is further large-scale study of $5 \mathrm{hmC}$ profiling in cancer at diagnosis and sequentially throughout therapeutic intervention to define subtype-specific patterns of $5 \mathrm{hmC}$, thus allowing us to interpret the heterogenous outcomes of patients with the same diseases. These studies would also have to define and evade epigenetic heterogeneity, which we know is a significant problem at a genetic level [154]. Furthermore, while predictive and prognostic markers are easily applicable to tumor samples at the time of extirpative surgery or diagnostic biopsy, the translation of $5 \mathrm{hmC}$ as a marker of therapeutic response is more complex. Currently, sequential tumor sampling through therapeutic intervention is not routine. This is for two reasons. First, as there are no reliable markers of response, there is no benefit to subjecting the patient to potentially harmful intervention. Second, repeated biopsy may be poorly tolerated by these patients. As such, the use of tissue $5 \mathrm{hmC}$ profiles as a dynamic measure of response will only be adopted if significant benefit to the patient can be demonstrated, non- (or minimally) invasive measurements can be identified or biopsy techniques can be made more tolerable.

Despite this, there is definite potential to add to the growing perception that NGS studies can make significant contributions to personalized medicine. There is certainly mounting evidence that $5 \mathrm{hmC}$ is involved in DNA methylation reprogramming, however, the exact mechanism by which this occurs still needs to be confirmed. It would also appear that $5 \mathrm{hmC}$ has a discrete role aside from a demethylation intermediate, as the mark persists at select loci at detectable (albeit low) levels, while the downstream $5 \mathrm{fC}$ and $5 \mathrm{caC}$ intermediates are rapidly turned over by base-excision repair [30]. It would also appear that there are significant correlations between $5 \mathrm{hmC}$ profiles and gene expression. However, the identification of the mechanisms in which this happens need to be explored. Irrespective of the mechanism, the tissue- and sample-specific profiles of $5 \mathrm{hmC}$ provide a unique opportunity for monitoring cell state, which may be highly applicable to archived material and therapeutic screens. However, although there has been progress in profiling $5 \mathrm{mC}$ from low-quantity and highly fragmented DNA as a result of formalin fixation and paraffin-embedded tissue [155], there has yet to be any study of $5 \mathrm{hmC}$ profiles in archival tissue or study of the effect of such tissue storage on $5 \mathrm{hmC}$ patterns, and this is clearly needed. This is especially important

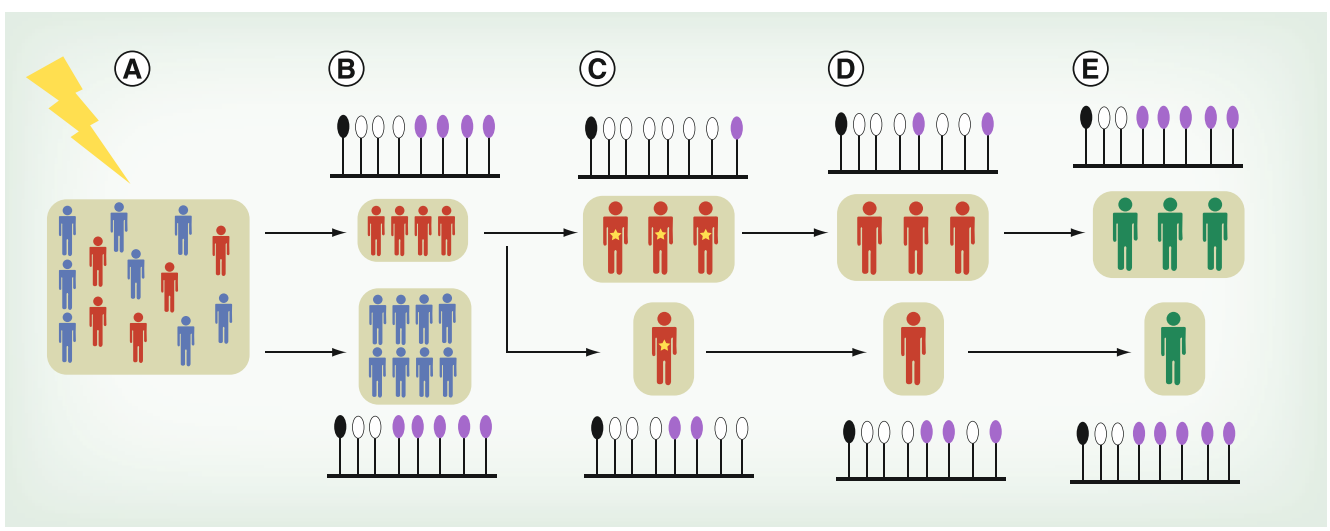

Figure 4. Potential model of 5-hydroxymethylcytosine biomarker use in the diagnosis and management of cancer. (A) Cohort exposed to risk factor for disease. (B) Red population have 5-hydroxymethylcytosine $(5 \mathrm{hmC})$ signature suggestive of sensitivity to this risk factor (black lollipops: 5-methylcytosine-marked CpGs; purple lollipops: 5hmC marked; white lollipops: unmarked CpGs). These patients can undergo close surveillance to allow early detection or pre-emptive treatment, if available. Blue patients can be reassured of low risk. (C) Patients develop cancer and can be stratified into treatment-sensitive or treatment-resistant groups to allow personalized therapy. (D) Response to treatment can be followed. (E) Return to 'normal' $5 \mathrm{hmC}$ tissue signature on cure. 
if fixation methods result in general oxidative damage to DNA. If possible, reliable profiling of archival tissue would provide a vast resource of well-annotated clinical samples to aid biomarker discovery.

The roles of TET enzymes and IDH obviously stretch beyond regulation of methylation and hydroxymethylation and teasing out the interactions will be interesting. In parallel to answering these mechanistic questions, such knowledge would allow the development of epigenetic drugs, which could reinstate normal $5 \mathrm{hmC}$ patterns, either globally or in a locus-specific manner. The substantial progress thus far gives promise of many exciting developments in this field over the coming years. Ultimately, the analysis of global $5 \mathrm{hmC}$ patterns, when combined with other epigenetic modifications and transcriptional information, will lead to a more refined understanding of tumor formation and stratification of specific cancer subtypes.

\section{Acknowledgements}

The authors thank D Sproul (MRC Human Genetics Unit, Edinburgh, UK) for invaluable comments on the manuscript. The authors also apologize to colleagues whose work could not be cited due to space limitations.

\section{Financial \& competing interests disclosure}

A Laird is supported by the Medical Research Council Scottish Clinical Pharmacology and Pathology Programme, The Royal College of Surgeons of Edinburgh Robertson's Trust and The Melville Trust for the Care and Cure of Cancer. $J$ Thomson is supported by the MARCAR project. Work in $R R$ Meehan's laboratory is supported by the Medical Research Council, the BBSRC and by the Innovative Medicine Initiative Joint Undertaking (IMI JU) under grant agreement number 115001 (MARCAR project). The authors have no other relevant affiliations or financial involvement with any organization or entity with a financial interest in or financial conflict with the subject matter or materials discussed in the manuscript apart from those disclosed.

No writing assistance was utilized in the production of this manuscript.

\section{Open Access}

This work is licensed under the Creative Commons Attribution-NonCommercial 3.0 Unported License. To view a copy of this license, visit http://creativecommons.org/ licenses/by-nc-nd/3.0

\section{Executive summary}

\section{Discovery \& technology}

- Standard bisulphite conversion and methylation-specific enzymatic digestion for the elucidation of methylation status cannot differentiate between 5-methylcytosine $(5 \mathrm{mC})$ and 5-hydroxymethylation (5hmC).

- Antibody-mediated 5hmC-enrichment techniques, glucosylation and purification, or selective restriction enzyme digestion can allow effective differential quantification of $5 \mathrm{mC}$ and $5 \mathrm{hmC}$.

\section{Function \& distribution}

- $5 \mathrm{hmC}$ is involved in DNA methylation reprogramming. However, the exact mechanism, whether passive or active, still needs to be confirmed. - $5 \mathrm{hmC}$ is likely to have a distinct role in marking and contributing to control of gene transcription.

\section{Hydroxymethylcytosine profiling defines cellular state}

- Global 5hmC levels are tissue-specific. 5hmC profiles are highly conserved in the livers of age-matched mice and are transcription-dependant.

- In the nongenotoxic carcinogen mouse model, global 5hmC perturbations alone were sufficient to stratify drug-exposed individuals from the control set, while $5 \mathrm{mC}$ and selective histone modifications did not always report exposure.

\section{Hydroxymethylcytosine patterns in cancer}

- General loss and cancer-specific redistribution of $5 \mathrm{hmC}$ has been shown. This may be through replication-dependant demethylation, TET inhibition or mutation, or metabolic manipulation by alteration of Krebs cycle enzymes.

\section{Clinical applicability}

- Tissue- and cell-specific 5hmC profiles provide a unique opportunity to monitor cellular state and show potential for translation to the clinic as diagnostic, prognostic or predictive biomarkers.

- Understanding the role of 5hmC, TETs and isocitrate by isocitrate dehydrogenase in carcinogenesis may provide novel therapeutic opportunities.

\section{References}

Papers of special note have been highlighted as:

- of interest

"

1 Berger SL, Kouzarides T, Shiekhattar R, Shilatifard A. An operational definition of epigenetics. Genes Dev. 23(7), 781-783 (2009).

2 Bird A. Perceptions of epigenetics. Nature 447(7143), 396-398 (2007).

3 Wongtawan T, Taylor JE, Lawson KA, Wilmut I, Pennings S. Histone H4K20me3 and HP1alpha are late heterochromatin markers in development, but present in undifferentiated embryonic stem cells. J. Cell. Sci. 124(Pt 11), 1878-1890 (2011).

4 Reik W. Stability and flexibility of epigenetic gene regulation in mammalian development. Nature 447(7143), 425-432 (2007). 
5 Hajkova P, Jeffries SJ, Lee C, Miller N, Jackson SP, Surani MA. Genome-wide reprogramming in the mouse germ line entails the base excision repair pathway. Science 329 (5987), 78-82 (2010).

6 Timp W, Feinberg AP. Cancer as a dysregulated epigenome allowing cellular growth advantage at the expense of the host. Nat. Rev. Cancer 13(7), 497-510 (2013).

7 Hansen KD, Timp W, Bravo HC et al. Increased methylation variation in epigenetic domains across cancer types. Nat. Genet. 43(8), 768-775 (2011).

8 Sproul D, Meehan RR. Genomic insights into cancer-associated aberrant $\mathrm{CpG}$ island hypermethylation. Brief Funct. Genomics 12(3), 174-190 (2013).

9 Sproul D, Kitchen RR, Nestor CE et al. Tissue of origin determines cancer-associated CpG island promoter hypermethylation patterns. Genome Biol. 13(10), R84 (2012).

10 Reddington JP, Perricone SM, Nestor CE et al. Redistribution of $\mathrm{H} 3 \mathrm{~K} 27 \mathrm{me} 3$ upon DNA hypomethylation results in derepression of Polycomb target genes. Genome Biol. 14(3), R25 (2013) (Epub ahead of print).

11 Cedar H, Bergman Y. Programming of DNA methylation patterns. Annu. Rev. Biochem. 81, 97-117 (2012).

12 Okano M, Bell DW, Haber DA, Li E. DNA methyltransferases Dnmt3a and Dnmt3b are essential for de novo methylation and mammalian development. Cell 99(3), 247-257 (1999).

13 Li E, Bestor TH, Jaenisch R. Targeted mutation of the DNA methyltransferase gene results in embryonic lethality. Cell 69(6), 915-926 (1992).

14 Ashe A, Morgan DK, Whitelaw NC et al. A genome-wide screen for modifiers of transgene variegation identifies genes with critical roles in development. Genome Biol. 9(12), R182 (2008).

15 Reddington JP, Pennings S, Meehan RR Non-canonical functions of the DNA methylome in gene regulation. Biochem. J. 451(1), 13-23 (2013).

16 Dunican DS, Ruzov A, Hackett JA, Meehan RR. xDnmt1 regulates transcriptional silencing in pre-MBT Xenopus embryos independently of its catalytic function. Development 135(7), 1295-1302 (2008).

17 Hervouet E, Vallette FM, Cartron PF. Dnmt3/transcription factor interactions as crucial players in targeted DNA methylation. Epigenetics 4(7), 487-499 (2009).

18 Riggs AD. X inactivation, differentiation, and DNA methylation. Cytogenet. Cell Genet. 14(1), 9-25 (1975).
19 Bestor T, Laudano A, Mattaliano R, Ingram $\mathrm{V}$. Cloning and sequencing of a cDNA encoding DNA methyltransferase of mouse cells. The carboxyl-terminal domain of the mammalian enzymes is related to bacterial restriction methyltransferases. J. Mol. Biol. 203(4), 971-983 (1988).

20 Ooi SK, Bestor TH. The colorful history of active DNA demethylation. Cell 133(7), 1145-1148 (2008).

21 Tahiliani M, Koh KP, Shen Y et al. Conversion of 5-methylcytosine to 5-hydroxymethylcytosine in mammalian DNA by MLL partner TET1. Science 324(5929), 930-935 (2009).

=IIdentification of TET enzymes that convert 5-methylcytosine to 5-hydroxymethylcytosine.

22 Koh KP, Rao A. DNA methylation and methylcytosine oxidation in cell fate decisions. Curr. Opin. Cell. Biol. 25(2), 152-161 (2013).

23 Shen L, Zhang Y. 5-Hydroxymethylcytosine: generation, fate, and genomic distribution. Curr. Opin. Cell. Biol. 25(3), 289-296 (2013).

24 Wyatt GR, Cohen SS. A new pyrimidine base from bacteriophage nucleic acids. Nature 170 (4338), 1072-1073 (1952).

25 Penn NW, Suwalski R, O’Riley C, Bojanowski $\mathrm{K}$, Yura R. The presence of

5-hydroxymethylcytosine in animal deoxyribonucleic acid. Biochem. J. 126(4), 781-790 (1972).

26 Kothari RM, Shankar V. 5-methylcytosine content in the vertebrate deoxyribonucleic acids: species specificity. J. Mol. Evol. 7(4), 325-329 (1976).

27 Kriaucionis S, Heintz N. The nuclear DNA base 5-hydroxymethylcytosine is present in Purkinje neurons and the brain. Science 324(5929), 929-930 (2009).

III Identification of mammalian 5-hydroxymethylcytosine.

28 Huang Y, Pastor WA, Shen Y, Tahiliani M, Liu DR, Rao A. The behaviour of 5-hydroxymethylcytosine in bisulfite sequencing. PLoS ONE 5(1), e8888 (2010).

29 Nestor C, Ruzov A, Meehan R, Dunican D. Enzymatic approaches and bisulfite sequencing cannot distinguish between 5-methylcytosine and 5-hydroxymethylcytosine in DNA. Biotechniques 48(4), 317-319 (2010).

30 Munzel M, Globisch D, Carell T. 5-hydroxymethylcytosine, the sixth base of the genome. Angew. Chem. Int. Ed. Engl. 50 (29), 6460-6468 (2011)

31 Clark SJ, Statham A, Stirzaker C, Molloy PL, Frommer M. DNA methylation: bisulphite modification and analysis. Nat. Protoc. 1(5), 2353-2364 (2006).
32 Clark SJ, Harrison J, Paul CL, Frommer M. High sensitivity mapping of methylated cytosines. Nucleic Acids Res. 22(15), 2990-2997 (1994).

33 Eads CA, Danenberg KD, Kawakami K et al. MethyLight: a high-throughput assay to measure DNA methylation. Nucleic Acids Res. 28(8), e32 (2000).

34 Pastor WA, Pape UJ, Huang Y et al. Genome-wide mapping of 5-hydroxymethylcytosine in embryonic stem cells. Nature 473(7347), 394-397 (2011).

35 Weber M, Davies JJ, Wittig D et al. Chromosome-wide and promoter-specific analyses identify sites of differential DNA methylation in normal and transformed human cells. Nat. Genet. 37(8), 853-862 (2005).

36 Weber M, Hellmann I, Stadler MB et al. Distribution, silencing potential and evolutionary impact of promoter DNA methylation in the human genome. Nat. Genet. 39(4), 457-466 (2007)

37 Ficz G, Branco MR, Seisenberger $S$ et al. Dynamic regulation of 5-hydroxymethylcytosine in mouse ES cells and during differentiation. Nature 473(7347), 398-402 (2011).

38 Huang Y, Pastor WA, Zepeda-Martinez JA, Rao A. The anti-CMS technique for genome-wide mapping of 5-hydroxymethylcytosine. Nat. Protoc. 7(10), 1897-1908 (2012).

39 Song CX, Szulwach KE, Fu Y et al. Selective chemical labeling reveals the genome-wide distribution of 5-hydroxymethylcytosine. Nat. Biotechnol. 29(1), 68-72 (2011).

40 Kinney SM, Chin HG, Vaisvila R et al. Tissue-specific distribution and dynamic changes of 5-hydroxymethylcytosine in mammalian genomes. J. Biol. Chem. 286(28), 24685-24693 (2011).

41 Nestor CE, Ottaviano R, Reddington J et al. Tissue type is a major modifier of the 5-hydroxymethylcytosine content of human genes. Genome Res. 22(3), 467-477 (2012).

- Potential of 5-hydroxymethylcytosine profile as a tissue identifier.

42 Booth MJ, Branco MR, Ficz G et al. Quantitative sequencing of 5-methylcytosine and 5-hydroxymethylcytosine at single-base resolution. Science 336(6083), 934-937 (2012).

43 Yu M, Hon GC, Szulwach KE et al. Base-resolution analysis of 5-hydroxymethylcytosine in the mammalian genome. Cell 149(6), 1368-1380 (2012).

44 Borst P, Sabatini R. Base J: discovery, biosynthesis, and possible functions. Annu. Rev. Microbiol. 62, 235-251 (2008). 
45 Ito S, D’Alessio AC, Taranova OV, Hong K, Sowers LC, Zhang Y. Role of Tet proteins in $5 \mathrm{mC}$ to $5 \mathrm{hmC}$ conversion, ES-cell selfrenewal and inner cell mass specification. Nature 466(7310), 1129-1133 (2010).

46 Freudenberg JM, Ghosh S, Lackford BL et al. Acute depletion of Tet1-dependent 5-hydroxymethylcytosine levels impairs LIF/Stat 3 signaling and results in loss of embryonic stem cell identity. Nucleic Acids Res. 40(8), 3364-3377 (2012).

47 Wu H, Zhang Y. Mechanisms and functions of Tet protein-mediated 5-methylcytosine oxidation. Genes Dev. 25(23), 2436-2452 (2011).

48 Guo JU, Su Y, Zhong C, Ming GL, Song H. Emerging roles of TET proteins and 5-hydroxymethylcytosines in active DNA demethylation and beyond. Cell Cycle 10 (16), 2662-2668 (2011)

49 Zhang J, Gao Q, Li P et al. S phase-dependent interaction with DNMT1 dictates the role of UHRF1 but not UHRF2 in DNA methylation maintenance. Cell Res. 21(12), 1723-1739 (2011).

50 Sharif J, Muto M, Takebayashi S et al. The SRA protein Np95 mediates epigenetic inheritance by recruiting Dnmt1 to methylated DNA. Nature 450(7171), 908-912 (2007).

51 Hashimoto H, Horton JR, Zhang X, Bostick M, Jacobsen SE, Cheng X. The SRA domain of UHRF1 flips 5-methylcytosine out of the DNA helix. Nature 455(7214), 826-829 (2008).

52 Valinluck V, Sowers LC. Endogenous cytosine damage products alter the site selectivity of human DNA maintenance methyltransferase DNMT1. Cancer Res. 67(3), 946-950 (2007).

53 Hashimoto H, Liu Y, Upadhyay AK et al. Recognition and potential mechanisms for replication and erasure of cytosine hydroxymethylation. Nucleic Acids Res. 40(11), 4841-4849 (2012).

54 Inoue A, Zhang Y. Replication-dependent loss of 5-hydroxymethylcytosine in mouse preimplantation embryos. Science 334(6053), 194 (2011).

55 Frauer C, Hoffmann T, Bultmann S et al. Recognition of 5-hydroxymethylcytosine by the Uhrf1 SRA domain. PLoS ONE 6(6), e21306 (2011).

56 Oda M, Oxley D, Dean W, Reik W. Regulation of lineage specific DNA hypomethylation in mouse trophectoderm. PLoS ONE 8(6), e68846 (2013).

57 He YF, Li BZ, Li Z et al. Tet-mediated formation of 5-carboxylcytosine and its excision by TDG in mammalian DNA. Science 333(6047), 1303-1307 (2011).
58 Ito S, Shen L, Dai Q et al. Tet proteins can convert 5-methylcytosine to 5-formylcytosine and 5-carboxylcytosine. Science 333(6047), 1300-1303 (2011).

59 Schiesser S, Hackner B, Pfaffeneder T et al. Mechanism and stem-cell activity of 5-carboxycytosine decarboxylation determined by isotope tracing. Angew. Chem. Int. Ed. Engl. 51(26), 6516-6520 (2012).

60 Smiley JA, Kundracik M, Landfried DA, Barnes VR Sr, Axhemi AA. Genes of the thymidine salvage pathway: thymine-7hydroxylase from a Rhodotorula glutinis cDNA library and iso-orotate decarboxylase from Neurospora crassa. Biochim. Biophys. Acta 1723(1-3), 256-264 (2005).

61 Rusmintratip V, Sowers LC. An unexpectedly high excision capacity for mispaired 5-hydroxymethyluracil in human cell extracts. Proc. Natl Acad. Sci. USA 97(26), 14183-14187 (2000).

62 Cortellino S, Xu J, Sannai M et al. Thymine DNA glycosylase is essential for active DNA demethylation by linked deamination-base excision repair. Cell 146(1), 67-79 (2011).

63 Hashimoto H, Hong S, Bhagwat AS, Zhang X, Cheng X. Excision of 5-hydroxymethyluracil and 5-carboxylcytosine by the thymine DNA glycosylase domain: its structural basis and implications for active DNA demethylation. Nucleic Acids Res. 40(20), 10203-10214 (2012).

64 Morgan HD, Dean W, Coker HA, Reik W, Petersen-Mahrt SK. Activation-induced cytidine deaminase deaminates 5-methylcytosine in DNA and is expressed in pluripotent tissues: implications for epigenetic reprogramming. J. Biol. Chem. 279(50), 52353-52360 (2004).

65 Popp C, Dean W, Feng S et al. Genome-wide erasure of DNA methylation in mouse primordial germ cells is affected by AID deficiency. Nature 463(7284), 1101-1105 (2010).

66 Nabel CS, Jia H, Ye Y et al. AID/APOBEC deaminases disfavor modified cytosines implicated in DNA demethylation. Nat. Chem. Biol. 8(9), 751-758 (2012).

67 Gong Z, Zhu JK. Active DNA demethylation by oxidation and repair. Cell Res. 21(12), 1649-1651 (2011).

68 Raiber EA, Beraldi D, Ficz G et al. Genomewide distribution of 5-formylcytosine in embryonic stem cells is associated with transcription and depends on thymine DNA glycosylase. Genome Biol. 13(8), R69 (2012).

69 Zhang L, Lu X, Lu J et al. Thymine DNA glycosylase specifically recognizes 5-carboxylcytosine-modified DNA. Nat. Chem. Biol. 8(4), 328-330 (2012).
70 Shen L, Wu H, Diep D et al. Genome-wide analysis reveals TET- and TDG-dependent 5 -methylcytosine oxidation dynamics. Cell 153(3), 692-706 (2013).

71 Song CX, Szulwach KE, Dai Q et al. Genome-wide profiling of 5-formylcytosine reveals its roles in epigenetic priming. Cell 153(3), 678-691 (2013).

72 Inoue A, Shen L, Dai Q, He C, Zhang Y. Generation and replication-dependent dilution of $5 \mathrm{fC}$ and $5 \mathrm{caC}$ during mouse preimplantation development. Cell Res. 21(12), 1670-1676 (2011).

73 Jin SG, Kadam S, Pfeifer GP. Examination of the specificity of DNA methylation profiling techniques towards 5-methylcytosine and 5-hydroxymethylcytosine. Nucleic Acids Res. 38(11), e125 (2010).

74 Valinluck V, Tsai HH, Rogstad DK, Burdzy A, Bird A, Sowers LC. Oxidative damage to methyl-CpG sequences inhibits the binding of the methyl-CpG binding domain (MBD) of methyl-CpG binding protein 2 (MeCP2). Nucleic Acids Res. 32(14), 4100-4108 (2004).

75 Yildirim O, Li R, Hung JH et al. Mbd3/NURD complex regulates expression of 5-hydroxymethylcytosine marked genes in embryonic stem cells. Cell 147(7), 1498-1510 (2011).

76 Mellen M, Ayata P, Dewell S, Kriaucionis S, Heintz N. MeCP2 binds to $5 \mathrm{hmC}$ enriched within active genes and accessible chromatin in the nervous system. Cell 151(7), 1417-1430 (2012).

77 Spruijt CG, Gnerlich F, Smits AH et al. Dynamic readers for 5-(hydroxy) methylcytosine and its oxidized derivatives. Cell 152(5), 1146-1159 (2013).

78 Meehan RR, Pennings S, Stancheva I. Lashings of DNA methylation, forkfuls of chromatin remodeling. Genes Dev. 15(24), 3231-3236 (2001).

79 Dennis K, Fan T, Geiman T, Yan Q, Muegge K. Lsh, a member of the SNF2 family, is required for genome-wide methylation. Genes Dev. 15(22), 2940-2944 (2001).

80 Jin SG, Wu X, Li AX, Pfeifer GP. Genomic mapping of 5-hydroxymethylcytosine in the human brain. Nucleic Acids Res. 39(12), 5015-5024 (2011).

81 Williams K, Christensen J, Pedersen MT et al. TET1 and hydroxymethylcytosine in transcription and DNA methylation fidelity. Nature 473(7347), 343-348 (2011).

82 Szulwach KE, Li X, Li Y et al. Integrating 5-hydroxymethylcytosine into the epigenomic landscape of human embryonic stem cells. PLoS Genet. 7(6), e1002154 (2011). 
83 Shi FT, Kim H, Lu W et al. Ten-eleven translocation 1 (tet1) is regulated by O-linked $N$-acetylglucosamine transferase (OGT) for target gene repression in mouse embryonic stem cells. J. Biol. Chem. 288(29), 20776-20784 (2013).

84 Deplus R, Delatte B, Schwinn MK et al. TET2 and TET3 regulate GlcNAcylation and H3K4 methylation through OGT and SET1/COMPASS. EMBO J. 32(5), 645-655 (2013).

85 Vella P, Scelfo A, Jammula $S$ et al. Tet proteins connect the $\mathrm{O}$-linked $\mathrm{N}$-acetylglucosamine transferase OGT to chromatin in embryonic stem cells. Mol. Cell 49(4), 645-656 (2013).

86 Chen Q, Chen Y, Bian C, Fujiki R, Yu X. TET2 promotes histone O-GlcNAcylation during gene transcription. Nature 493(7433), 561-564 (2013).

87 Stroud H, Feng S, Morey Kinney S, Pradhan S, Jacobsen SE.

5-hydroxymethylcytosine is associated with enhancers and gene bodies in human embryonic stem cells. Genome Biol. 12(6), R54 (2011).

88 Brodie Of Brodie EB, Nicolay S, Touchon M et al. From DNA sequence analysis to modeling replication in the human genome. Phys. Rev. Lett. 94(24), 248103 (2005).

89 Touchon M, Nicolay S, Audit B et al. Replication-associated strand asymmetries in mammalian genomes: toward detection of replication origins. Proc. Natl Acad. Sci. USA 102(28), 9836-9841 (2005).

90 Huvet M, Nicolay S, Touchon M et al. Human gene organization driven by the coordination of replication and transcription. Genome Res. 17(9), 1278-1285 (2007).

91 Jin SG, Jiang Y, Qiu R et al. 5-hydroxymethylcytosine is strongly depleted in human cancers but its levels do not correlate with IDH1 mutations. Cancer Res. 71(24), 7360-7365 (2011).

- Defines loss of 5-hydroxymethylation in multiple cancers.

92 Lister R, Mukamel EA, Nery JR et al. Global epigenomic reconfiguration during mammalian brain development. Science 341(6146), 1237905 (2013).

93 Thomson JP, Hunter JM, Lempiainen $\mathrm{H}$ et al. Dynamic changes in 5-hydroxymethylation signatures underpin early and late events in drug exposed liver. Nucleic Acids Res. 41(11), 5639-5654 (2013).

"I- Defines 5-hydroxymethylation as a dynamic marker of exposure to the nongenotoxic carcinogen phenobarbital and liver development, and highlights the potential use of 5-hydroxymethylation as a marker of exposure to environmental stimuli or therapeutic intervention.

94 Thomson JP, Lempiainen H, Hackett JA et al. Non-genotoxic carcinogen exposure induces defined changes in the 5-hydroxymethylome. Genome Biol. 13(10), R93 (2012).

95 Peraino C, Fry RJ, Staffeldt E. Reduction and enhancement by phenobarbital of hepatocarcinogenesis induced in the rat by 2-acetylaminofluorene. Cancer Res. 31(10), 1506-1512 (1971).

96 Becker FF. Morphological classification of mouse liver tumors based on biological characteristics. Cancer Res. 42(10), 3918-3923 (1982)

97 Bachman AN, Phillips JM, Goodman JI. Phenobarbital induces progressive patterns of GC-rich and gene-specific altered DNA methylation in the liver of tumor-prone B6C3F1 mice. Toxicol. Sci. 91(2), 393-405 (2006).

98 Aydinlik H, Nguyen TD, Moennikes O, Buchmann A, Schwarz M. Selective pressure during tumor promotion by phenobarbital leads to clonal outgrowth of betacatenin-mutated mouse liver tumors. Oncogene 20(53), 7812-7816 (2001).

99 Lee GH. Paradoxical effects of phenobarbital on mouse hepatocarcinogenesis. Toxicol. Pathol. 28(2), 215-225 (2000).

100 Mutoh S, Sobhany M, Moore R et al. Phenobarbital indirectly activates the constitutive active androstane receptor (CAR) by inhibition of epidermal growth factor receptor signaling. Sci. Signal. 6(274), ra31 (2013).

101 Lee KW, Pausova Z. Cigarette smoking and DNA methylation. Front. Genet. 4, 132 (2013).

102 Haffner MC, Chaux A, Meeker AK et al. Global 5-hydroxymethylcytosine content is significantly reduced in tissue stem/progenitor cell compartments and in human cancers. Oncotarget 2(8), 627-637 (2011).

103 Ehrlich M. DNA hypomethylation in cancer cells. Epigenomics 1(2), 239-259 (2009).

104 Bhutani N, Burns DM, Blau HM. DNA demethylation dynamics. Cell 146(6), 866-872 (2011).

105 Iqbal K, Jin SG, Pfeifer GP, Szabo PE. Reprogramming of the paternal genome upon fertilization involves genome-wide oxidation of 5-methylcytosine. Proc. Natl Acad. Sci. USA 108(9), 3642-3647 (2011).

106 Wossidlo M, Nakamura T, Lepikhov Ket al. 5-Hydroxymethylcytosine in the mammalian zygote is linked with epigenetic reprogramming. Nat. Commun. 2, 241 (2011).

107 Ono R, Taki T, Taketani T, Taniwaki M, Kobayashi H, Hayashi Y. LCX, leukemia- associated protein with a CXXC domain, is fused to MLL in acute myeloid leukemia with trilineage dysplasia having $\mathrm{t}(10 ; 11)(\mathrm{q} 22 ; \mathrm{q} 23)$. Cancer Res. 62(14), 4075-4080 (2002).

108 Lorsbach RB, Moore J, Mathew S, Raimondi SC, Mukatira ST, Downing JR. TET1, a member of a novel protein family, is fused to MLL in acute myeloid leukemia containing the $\mathrm{t}(10 ; 11)(\mathrm{q} 22 ; \mathrm{q} 23)$. Leukemia 17(3), 637-641 (2003).

109 Hsu CH, Peng KL, Kang ML et al. TET1 suppresses cancer invasion by activating the tissue inhibitors of metalloproteinases. Cell Rep. 2(3), 568-579 (2012).

110 Sun M, Song CX, Huang $\mathrm{H}$ et al. HMGA2/TET1/HOXA9 signaling pathway regulates breast cancer growth and metastasis. Proc. Natl Acad. Sci. USA 110(24), 9920-9925 (2013).

- Highlights the utility of 5-hydroxymethylation as a diagnostic and prognostic marker in cancer, associating this mechanistically with TET1 expression.

111 Liu C, Liu L, Chen X et al. Decrease of 5-hydroxymethylcytosine is associated with progression of hepatocellular carcinoma through downregulation of TET1. PLoS ONE 8(5), e62828 (2013).

112 Lian CG, Xu Y, Ceol C et al. Loss of 5-hydroxymethylcytosine is an epigenetic hallmark of melanoma. Cell 150(6), 1135-1146 (2012).

" $\quad$ Evidence of 5-hydroxymethylation as a diagnostic and prognostic marker in melanoma, implicating TET and isocitrate dehydrogenase mechanistically. Also highlights the potential therapeutic opportunities for 5-hydroxymethylation and TET enzymes.

113 Bhattacharyya S, Yu Y, Suzuki M et al. Genome-wide hydroxymethylation tested using the HELP-GT assay shows redistribution in cancer. Nucleic Acids Res. 41(16), e157 (2013).

114 Wood LD, Parsons DW, Jones S et al. The genomic landscapes of human breast and colorectal cancers. Science 318(5853), 1108-1113 (2007).

115 Sjoblom T, Jones S, Wood LD et al. The consensus coding sequences of human breast and colorectal cancers. Science 314(5797), 268-274 (2006).

116 Kan Z, Jaiswal BS, Stinson J et al. Diverse somatic mutation patterns and pathway alterations in human cancers. Nature 466(7308), 869-873 (2010).

117 Berger MF, Lawrence MS, Demichelis F et al. The genomic complexity of primary human prostate cancer. Nature 470 (7333), 214-220 (2011). 
118 Abdel-Wahab O, Mullally A, Hedvat C et al. Genetic characterization of TET1, TET2, and TET3 alterations in myeloid malignancies. Blood 114(1), 144-147 (2009).

119 Delhommeau F, Dupont S, Della Valle V et al. Mutation in TET2 in myeloid cancers. N. Engl. J. Med. 360(22), 2289-2301 (2009).

120 Jankowska AM, Szpurka H, Tiu RV et al. Loss of heterozygosity 4q24 and TET2 mutations associated with myelodysplastic/myeloproliferative neoplasms. Blood 113(25), 6403-6410 (2009)

121 Kohlmann A, Grossmann V, Klein HU et al. Next-generation sequencing technology reveals a characteristic pattern of molecular mutations in $72.8 \%$ of chronic myelomonocytic leukemia by detecting frequent alterations in TET2, CBL, RAS, and RUNX1. J. Clin. Oncol. 28(24), 3858-3865 (2010).

122 Langemeijer SM, Kuiper RP, Berends M et al. Acquired mutations in TET2 are common in myelodysplastic syndromes. Nat. Genet. 41(7), 838-842 (2009).

123 Tefferi A, Lim KH, Abdel-Wahab O et al. Detection of mutant TET2 in myeloid malignancies other than myeloproliferative neoplasms: CMML, MDS, MDS/MPN and AML. Leukemia 23(7), 1343-1345 (2009).

124 Quivoron C, Couronne L, Della Valle V et al. TET2 inactivation results in pleiotropic hematopoietic abnormalities in mouse and is a recurrent event during human lymphomagenesis. Cancer Cell 20(1), 25-38 (2011).

125 Koh KP, Yabuuchi A, Rao S et al. Tet1 and Tet 2 regulate 5 -hydroxymethylcytosine production and cell lineage specification in mouse embryonic stem cells. Cell Stem Cell 8(2), 200-213 (2011).

126 Ko M, Bandukwala HS, An J et al. Ten-eleventranslocation 2 (TET2) negatively regulates homeostasis and differentiation of hematopoietic stem cells in mice. Proc. Natl Acad. Sci. USA 108(35), 14566-14571 (2011).

$127 \mathrm{Li}$ Z, Cai X, Cai CL et al. Deletion of Tet2 in mice leads to dysregulated hematopoietic stem cells and subsequent development of myeloid malignancies. Blood 118(17), 4509-4518 (2011).

128 Moran-Crusio K, Reavie L, Shih A et al. Tet2 loss leads to increased hematopoietic stem cell self-renewal and myeloid transformation. Cancer Cell 20(1), 11-24 (2011).

129 Reitman ZJ, Jin G, Karoly ED et al. Profiling the effects of isocitrate dehydrogenase 1 and 2 mutations on the cellular metabolome. Proc. Natl Acad. Sci. USA 108(8), 3270-3275 (2011).

$130 \mathrm{Xu}$ W, Yang H, Liu Y et al. Oncometabolite 2-hydroxyglutarate is a competitive inhibitor of alpha-ketoglutarate-dependent dioxygenases. Cancer Cell 19(1), 17-30 (2011).

131 Dang L, White DW, Gross S et al. Cancerassociated IDH1 mutations produce 2-hydroxyglutarate. Nature 462(7274), 739-744 (2009).

132 Ward PS, Patel J, Wise DR et al. The common feature of leukemia-associated IDH1 and IDH2 mutations is a neomorphic enzyme activity converting alpha-ketoglutarate to 2-hydroxyglutarate. Cancer Cell 17(3), 225-234 (2010).

133 Chowdhury R, Yeoh KK, Tian YM et al. The oncometabolite 2-hydroxyglutarate inhibits histone lysine demethylases. EMBO Rep. 12(5), 463-469 (2011).

134 Koivunen P, Lee S, Duncan CG et al. Transformation by the (R)-enantiomer of 2-hydroxyglutarate linked to EGLN activation. Nature 483(7390), 484-488 (2012).

135 Losman JA, Looper RE, Koivunen P et al. (R)-2-hydroxyglutarate is sufficient to promote leukemogenesis and its effects are reversible. Science 339(6127), 1621-1625 (2013).

136 Abdel-Wahab O, Manshouri T, Patel J et al. Genetic analysis of transforming events that convert chronic myeloproliferative neoplasms to leukemias. Cancer Res. 70(2), 447-452 (2010).

137 Parsons DW, Jones S, Zhang X et al. An integrated genomic analysis of human glioblastoma multiforme. Science 321(5897), 1807-1812 (2008).

138 Yan H, Parsons DW, Jin G et al. IDH1 and IDH2 mutations in gliomas. N. Engl. J. Med. 360(8), 765-773 (2009).

139 Kang MR, Kim MS, Oh JE et al. Mutational analysis of IDH1 codon 132 in glioblastomas and other common cancers. Int. J. Cancer 125(2), 353-355 (2009).

140 Murugan AK, Bojdani E, Xing M. Identification and functional characterization of isocitrate dehydrogenase 1 (IDH1) mutations in thyroid cancer. Biochem. Biophys. Res. Commun. 393(3), 555-559 (2010).

141 Wang P, Dong Q, Zhang C et al. Mutations in isocitrate dehydrogenase 1 and 2 occur frequently in intrahepatic cholangiocarcinomas and share hypermethylation targets with glioblastomas. Oncogene 32 (25), 3091-3100 (2013).

142 Noushmehr H, Weisenberger DJ, Diefes K et al. Identification of a CpG island methylator phenotype that defines a distinct subgroup of glioma. Cancer Cell 17(5), 510-522 (2010).

143 Kraus TF, Globisch D, Wagner M et al. Low values of 5-hydroxymethylcytosine ( $5 \mathrm{hmC})$, the "sixth base," are associated with anaplasia in human brain tumors. Int. J. Cancer 131(7), 1577-1590 (2012)

144 Muller T, Gessi M, Waha A et al. Nuclear exclusion of TET1 is associated with loss of 5-hydroxymethylcytosine in IDH1 wild-type gliomas. Am. J. Pathol. 181(2), 675-683 (2012).

145 Orr BA, Haffner MC, Nelson WG, Yegnasubramanian S, Eberhart CG. Decreased 5-hydroxymethylcytosine is associated with neural progenitor phenotype in normal brain and shorter survival in malignant glioma. PLoS ONE 7(7), e41036 (2012).

146 Bruick RK, McKnight SL. A conserved family of prolyl-4-hydroxylases that modify HIF. Science 294(5545), 1337-1340 (2001).

147 Tsukada Y, Fang J, Erdjument-Bromage H et al. Histone demethylation by a family of JmjC domain-containing proteins. Nature 439(7078), 811-816 (2006).

148 Baysal BE, Ferrell RE, Willett-Brozick JE et al. Mutations in SDHD, a mitochondrial complex II gene, in hereditary paraganglioma. Science 287(5454), 848-851 (2000).

149 Hao HX, Khalimonchuk O, Schraders M et al. $S D H 5$, a gene required for flavination of succinate dehydrogenase, is mutated in paraganglioma. Science 325(5944), 1139-1142 (2009).

150 Bayley JP, Kunst HP, Cascon A et al. SDHAF2 mutations in familial and sporadic paraganglioma and phaeochromocytoma. Lancet Oncol. 11(4), 366-372 (2010).

151 Tomlinson IP, Alam NA, Rowan AJ et al. Germline mutations in $\mathrm{FH}$ predispose to dominantly inherited uterine fibroids, skin leiomyomata and papillary renal cell cancer. Nat. Genet. 30(4), 406-410 (2002).

152 Letouze E, Martinelli C, Loriot C et al. SDH mutations establish a hypermethylator phenotype in paraganglioma. Cancer Cell 23(6), 739-752 (2013).

153 Xiao M, Yang H, Xu W et al. Inhibition of alpha-KG-dependent histone and DNA demethylases by fumarate and succinate that are accumulated in mutations of $\mathrm{FH}$ and $\mathrm{SDH}$ tumor suppressors. Genes Dev. 26(12), 1326-1338 (2012).

154 Gerlinger M, Rowan AJ, Horswell S et al. Intratumor heterogeneity and branched evolution revealed by multiregion sequencing N. Engl. J. Med. 366(10), 883-892 (2012).

155 Thirlwell C, Eymard M, Feber A et al. Genome-wide DNA methylation analysis of archival formalin-fixed paraffin-embedded tissue using the Illumina Infinium HumanMethylation27 BeadChip. Methods 52(3), 248-254 (2010). 